\title{
Methane preconcentration by adsorption: a methodology for materials and conditions selection
}

\author{
Simon Eyer • Nicholas P. Stadie - Andreas Borgschulte • \\ Lukas Emmenegger · Joachim Mohn
}

Received: 8 August 2013/Revised: 4 March 2014/Accepted: 1 April 2014/Published online: 26 April 2014

(C) The Author(s) 2014. This article is published with open access at Springerlink.com

\begin{abstract}
Methane $\left(\mathrm{CH}_{4}\right)$ adsorption has been widely studied, mainly in the context of natural gas purification. A much less prominent, but highly relevant application is the preconcentration of $\mathrm{CH}_{4}$ from ambient air. In this study, we compare six different commercial adsorbent materials with respect to their effectiveness for methane preconcentration: a macroporous polymeric resin (HayeSep D), multi-walled carbon nanotubes, two microporous metal-organic frameworks (HKUST-1 and ZIF-8), and two zeolites (5A and 13X). The most relevant properties, such as isosteric enthalpy of adsorption, specific surface area and the selectivity for $\mathrm{CH}_{4}$ adsorption over $\mathrm{N}_{2}$ were characterized by analyzing adsorption/desorption isotherms. Using these parameters, we discuss the tested adsorbents with respect to the most important properties and identify the most promising candidates. Furthermore we identify the experimental conditions that are expected to give the best results with respect to practical applications.
\end{abstract}

Keywords Methane - Adsorption - Isosteric enthalpy · Gas selectivity $\cdot$ Specific surface area $\cdot$ Preconcentration

Electronic supplementary material The online version of this article (doi:10.1007/s10450-014-9609-9) contains supplementary material, which is available to authorized users.

S. Eyer $(\bowtie) \cdot$ L. Emmenegger $\cdot$ J. Mohn

Empa, Laboratory for Air Pollution \& Environmental

Technology, Überlandstrasse 129, 8600 Dübendorf, Switzerland

e-mail: simon.eyer@empa.ch

N. P. Stadie · A. Borgschulte

Empa, Laboratory for Hydrogen \& Energy, Überlandstrasse 129 ,

8600 Dübendorf, Switzerland

\section{Introduction}

Global warming resulting from anthropogenically emitted greenhouse gases (GHGs) is an important environmental issue. After $\mathrm{CO}_{2}$, methane $\left(\mathrm{CH}_{4}\right)$ has the highest contribution to the greenhouse effect and on a per-molecule basis, its global warming potential is 25 times higher compared to $\mathrm{CO}_{2}$ on a 100 year timescale (Solomon 2007). Global $\mathrm{CH}_{4}$ emissions are relatively well quantified, but the strength of the individual source components and their trends are not (Solomon 2007). By measuring the stable isotopic composition of $\mathrm{CH}_{4}$ in ambient air with high accuracy $\left(\approx 1 \mathrm{ppt}=10^{-12} \mathrm{~mol} / \mathrm{mol}\right)$, the major source processes can be identified. The standard way to achieve such measurements is isotope-ratio mass-spectrometry, which is generally laboratory-based (Werner and Brand 2001). However, recently developed infrared laser-based measuring systems are an attractive alternative, especially for field measurements. Such field measurements based on laser spectroscopy have been shown to yield reliable results at high temporal resolution for the stable isotopes of $\mathrm{CO}_{2}$ (Tuzson et al. 2008, 2011). However, for the less abundant GHGs, such as $\mathrm{N}_{2} \mathrm{O}$ and $\mathrm{CH}_{4}$, preconcentration of the target species is required (Mohn et al. 2010, 2012) to reach a precision of $0.1 \%$ for the ratio of the isotopologues. Otherwise analysis is limited to source studies at high mixing ratios (Wunderlin et al. 2012, 2013; Koester et al. 2013). An efficient way for methane preconcentration is achieved by performing temperature cycles on suitable adsorbent materials (Bock et al. 2010). For continuous monitoring of $\mathrm{CH}_{4}$ isotopologues in ambient air under field conditions, temperatures that do not require the use of liquid nitrogen are preferred.

High-precision laser spectroscopy by mid-infrared absorption comprises the usage of multipass absorption cells with a volume of up to one liter, generally at $1-10 \mathrm{kPa}$ 
(Mohn et al. 2010). The best spectroscopic precision is typically obtained at $\mathrm{CH}_{4}$ mixing ratios of several hundred ppm. This implies the preconcentration by a factor $>100$, given typical ambient mixing ratios of $1.8 \mathrm{ppm}$. For adsorptive preconcentration, it is necessary to use an adsorbent material with high $\mathrm{CH}_{4}$ adsorption capacity, i. e. high specific surface area, and a high selectivity for $\mathrm{CH}_{4}$ over $\mathrm{N}_{2}$. Selectivity for $\mathrm{CO}_{2}$ and $\mathrm{H}_{2} \mathrm{O}$ is less important because these components can be quantitatively removed with a typical pretreatment (Mohn et al. 2010; Bock et al. 2010). Additionally, quantitative adsorption/desorption of the analyte is required to avoid kinetic isotopic fractionation effects due to subtle but characteristic differences in the enthalpy of adsorption of individual $\mathrm{CH}_{4}$ isotopologues (Phillips and Hook 1967; Fayet et al. 1990). The most frequently used preconcentration adsorbents for $\mathrm{CH}_{4}, \mathrm{~N}_{2} \mathrm{O}$ and volatile organic compounds (VOC) are HayeSep polymers (Mohn et al. 2010; Bock et al. 2010; Reimann et al. 2008) and carbon-based materials (Thammakhet et al. 2005; Saridara et al. 2010; Wu et al. 2003; Wong et al. 2013; Dettmer and Engewald 2002; Falkovich and Rudich 2001; Li et al. 2012). Recently, multiwalled carbon nanotubes (MWCNT) were reported to yield the highest uptake of a selection of carbon-based adsorbents (Saridara et al. 2010). Porous zeolites may also be a valuable alternative, because of their high surface area and high potential selectivity due to the molecular sieve effect (Yaremov et al. 2013; Delgado et al. 2013; Wang et al. 1998). For example, molecular sieves have been shown to be appealing for the application of $\mathrm{CO}_{2} / \mathrm{CH}_{4}$ separation (Lu et al. 2013). More recently, a different class of adsorbent materials known as metal-organic frameworks (MOFs), which exhibits exceptionally large specific surface areas, has shown to be highly promising for applications in gas storage and gas separation (Li et al. 1999, 2009; Mendoza-Cortes 2010; Dren et al. 2004; Wu 2010; Moellmer et al. 2011). Using adsorbents under material-specific optimal conditions for selective $\mathrm{CH}_{4}$ adsorption may greatly increase the performance of applications such as preconcentration of $\mathrm{CH}_{4}$ from ambient air for laser spectroscopic analysis.

In this study, a selection of six promising commercially available adsorbents are compared regarding $\mathrm{CH}_{4}$ adsorption amount, $\mathrm{CH}_{4} / \mathrm{N}_{2}$ selectivity and isosteric enthalpy : a macroporous polymeric resin (HayeSep D), MWCNT, two microporous metal-organic frameworks (HKUST-1 and ZIF-8), and two zeolites (5A and 13X). Adsorption measurements of $\mathrm{CH}_{4}$ and $\mathrm{N}_{2}$ at four temperatures between 77 and $296 \mathrm{~K}$ were performed. The specific surface area was determined using $\mathrm{N}_{2}$ and $\mathrm{CH}_{4}$ adsorption isotherms at 77 $\mathrm{K}$, and the isosteric enthalpy was calculated using a modelindependent method. This is to our knowledge the first systematic investigation of such a variety of different adsorbent materials for $\mathrm{CH}_{4}$ with the aim of finding a material that is suitable for analytical applications.

\section{Materials and methods}

The investigated materials were obtained from the following sources: HayeSep D (100/120 mesh), the MOFs HKUST-1 (D50 $15.96 \mu \mathrm{m}$ ) and ZIF-8 (D50 $4.9 \mu \mathrm{m})$, as well as the zeolites Z5A and Z13X (both 100/120 mesh) from Sigma Aldrich (Switzerland). The MWCNT ( $>95$ $\%,<8 \mathrm{~nm}$ ) were purchased from Cheap Tubes Inc (USA). All adsorption measurements were performed with a Belsorp Max (BEL Inc., Japan) volumetric Sieverts apparatus. Methane and nitrogen gas were obtained from Messer AG (Switzerland), with purities of 99.995 and $99.9999 \%$, respectively.

During experiments, approximately $500 \mathrm{mg}$ samples were held in a stable cold bath at temperatures of 296, 273, 196 and $77 \mathrm{~K}( \pm 0.2 \mathrm{~K})$, corresponding to room temperature, ice water, dry ice and liquid nitrogen, respectively. Adsorption measurements were performed between 0 and $100 \mathrm{kPa}$ and followed by desorption measurement at each temperature. For methane adsorption measurements at $77 \mathrm{~K}$ the pressure range was set to $0-1.8 \mathrm{kPa}$ and desorption measurements were not possible, probably because the methane froze on the surface of the adsorbents. The accuracy of the volumetric Sieverts apparatus is determined by the resolution of the pressure gauge, among other factors. The overall uncertainty of an individual data point is approximately $\pm 0.015 \mathrm{mmol} / \mathrm{g}$ upon repeated measurements.

\section{Analysis}

To determine the most suitable material for $\mathrm{CH}_{4}$ preconcentration, specific uptake, selectivity and isosteric enthalpy of adsorption should ideally be investigated in a wide range of temperature and pressure. The relevant parameters may then be extracted from the measured isotherms and estimated for practical working conditions in the scheduled application. For this analysis, a fitting equation and/or model is necessary to interpolate the data. In the following sections, we briefly outline the methods used.

\subsection{Adsorption models}

The Langmuir model is the simplest model of physical adsorption of gas on a surface, beyond Henry's law. It is useful for adsorption systems where the mechanism is monolayer-like and the adsorption sites are relatively homogeneous since only one binding energy is used. At low temperatures and on specific adsorbents where multiple layers cannot easily exist, it provides a good quality of fit to adsorption data and the isosteric enthalpy and specific surface area can be readily obtained (Gregg and Sing 1991). 
The Brunauer-Emmett-Teller (BET) model is an extension of the Langmuir model which allows for multilayer formation where the binding energy of sites in the second layer and higher is set equal to the heat of liquefaction. Beyond the initial point of multilayer formation (referred to as Point B), adsorption proceeds nearly linearly with respect to pressure, and the specific surface area of the adsorbent can thus readily be determined. This model is useful for characterizing a wide variety of sorbents at low temperature (usually with $\mathrm{N} 2$ at $77 \mathrm{~K}$ ) and although the limitations of this method have been widely discussed, it remains in common use due to its simplicity (Sing 2001). For the purpose of this study, the low temperature adsorption measurements $(77 \mathrm{~K})$ were analyzed with both the Langmuir and the BET model to deduce adsorption surface areas. The quality of fit of both models is evaluated based on the residual of the fit given in the Online Resource.

However, adsorption models which can account for phenomena at higher temperatures and pressures are more complicated, as has been previously discussed in great detail (e.g. Bimbo et al. 2011). The data in this study were fitted, for example, with a generalized Langmuir type equation which can account for adsorption on heterogeneous surfaces. Though fits with even larger numbers of fitting parameters were attempted, the range of temperatures and pressures measured in this study were not conducive to its practical use. A common method for fitting adsorption data over a large range of temperature is to use a virial-type equation (1) (Czepirski and Jagiello 1989; Stadie 2012). This model-less approach is beneficial in that it relies on relatively few fitting parameters and retains a very simple expression for the isosteric enthalpy of adsorption.

$\ln \left(\frac{p}{n}\right)=\frac{1}{T} \sum_{i} a_{i} n^{i}+\sum_{i} b_{i} n^{i}$

where $n$ is the molar amount of gas adsorbed per unit weight, $p$ is the equilibrium pressure, $T$ the temperature and $a_{i}$ and $b_{i}$ are the Virial coefficients of order $i$. From this formula, the isosteric enthalpy is found by employing the Clausius-Clapeyron relation (2) (Stadie et al. 2013).

$$
-\Delta H_{a d s}=R\left(\frac{\partial \ln p}{\partial(1 / T)}\right)_{n}=R \sum_{i} a_{i} n^{i}
$$

The temperature dependence of the isosteric enthalpy is not accessible in this method, and the pressure dependence is known to be susceptible to various pitfalls. For this reason, we focus on the value in the Henry's law limit $(p \longrightarrow 0)(3)$.

$$
-\Delta H_{0}=R \lim _{n \longrightarrow 0} \sum_{i} a_{i} n^{i}=R a_{0}
$$

The simplest approach, for comparison purposes, is to fit the adsorption data using a linear interpolation method and applying the simplified Clausius-Clapeyron equation (4). $\ln (p)=-\frac{\Delta H_{a d s}}{R T}+\epsilon$

where $R$ is the molar gas constant and $\epsilon$ is a constant. This is often unreliable for obtaining anything except an approximation of the isosteric enthalpy of adsorption (the Henry's law value) via the Clausius-Clapeyron equation and relies on large numbers of data points to be successful (Stadie 2012).

Once a fitting equation has been selected, the adsorptive selectivity between two gas species can also be estimated using gas uptake data. In this study, we focus on estimating the selectivity in two ways defined by the parameters $X$ and $Y$.

$$
\begin{aligned}
X & =\frac{n_{C H_{4}}(p, T)}{n_{N_{2}}(p, T)} \\
Y & =\frac{\Delta H_{a d s}^{C H_{4}}}{\Delta H_{a d s}^{N_{2}}}(p=0, T)
\end{aligned}
$$

Parameter $X$ is the ratio of adsorption uptake of $\mathrm{CH}_{4}$ and $\mathrm{N}_{2}$ under identical conditions and $Y$ is the ratio of the $\Delta H_{a d s}$ for $\mathrm{CH}_{4}$ and $\mathrm{N}_{2}$. The interpretation of these coefficients will be discussed in detail in Sect. 4.4.

\section{Results and discussion}

From a phenomenological point of view, there is a considerable difference between the adsorption of gases at near ambient temperatures (above $196 \mathrm{~K}$ ) and cryogenic temperature $(77 \mathrm{~K})$, where effects due to a nearly fully covered surface have to be taken into account. Therefore, we have chosen to focus on the temperature range of 196-296 K to determine isosteric enthalpy and selectivity, while the specific surface area was determined from the data measured at $77 \mathrm{~K}$. With these important parameters, we discuss the possible application of the evaluated materials for preconcentration.

\subsection{Adsorption of $\mathrm{CH}_{4}$ and $\mathrm{N}_{2}$ in the temperature range of $196-296 \mathrm{~K}$}

At temperatures 196, 273 and $296 \mathrm{~K}$, all of the adsorbents exhibit Type I behavior with respect to $\mathrm{N}_{2}$ and $\mathrm{CH}_{4}$ adsorption (Gregg and Sing 1991). In this temperature region the best global fit of adsorption data was obtained using the model-less virial approach in second order. Information on the model selection and the residual of the fits are given in the Online Resource. In Figs. 1, 2, 3, 4, 5, 6 the measured $\mathrm{CH}_{4}$ and $\mathrm{N}_{2}$ adsorption (closed symbols) and desorption isotherms (open symbols) are given. Based on 


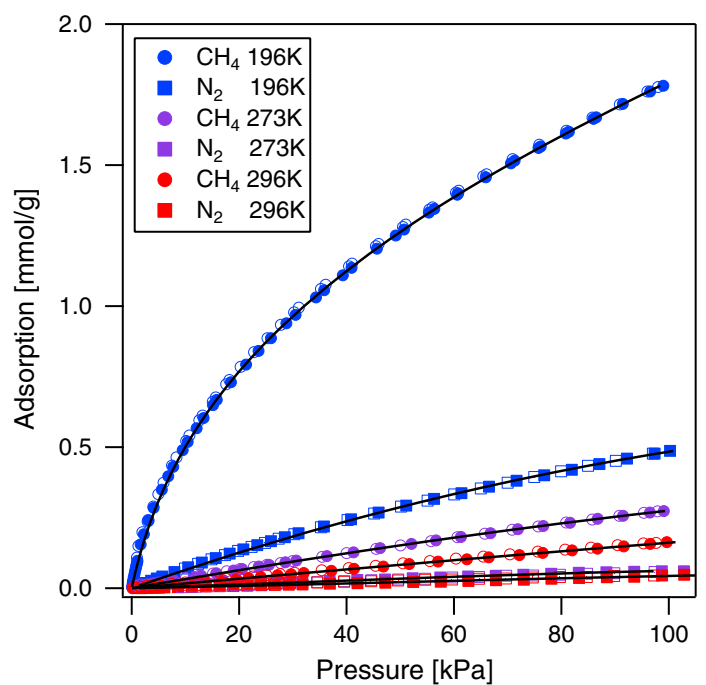

Fig. 1 Adsorption isotherms of $\mathrm{CH}_{4}$ and $\mathrm{N}_{2}$ by HayeSep D at 196, 273 and 296 K. Filled symbols indicate adsorption and empty symbols indicate desorption measurement points

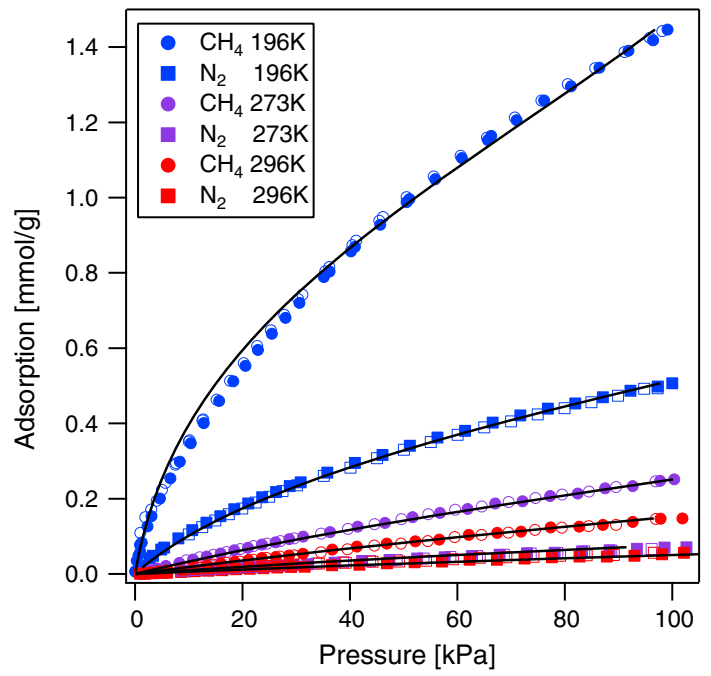

Fig. 2 Adsorption isotherms of $\mathrm{CH}_{4}$ and $\mathrm{N}_{2}$ by MWCNT at 196, 273 and 296 K. Filled symbols indicate adsorption and empty symbols indicate desorption measurement points

the excellent agreement of adsorption and desorption measurements significant hysteresis effects can be excluded. The highest adsorption capacity for $\mathrm{CH}_{4}$ and $\mathrm{N}_{2}$ in the temperature range of 196-296 K was observed for HKUST-1. The zeolites exhibit a high adsorption capacity of $\mathrm{CH}_{4}$ especially at low pressures $(<10 \mathrm{kPa})$, but the difference in adsorption capacity of $\mathrm{CH}_{4}$ and $\mathrm{N}_{2}$ is significantly smaller than for the other candidate materials in this study.

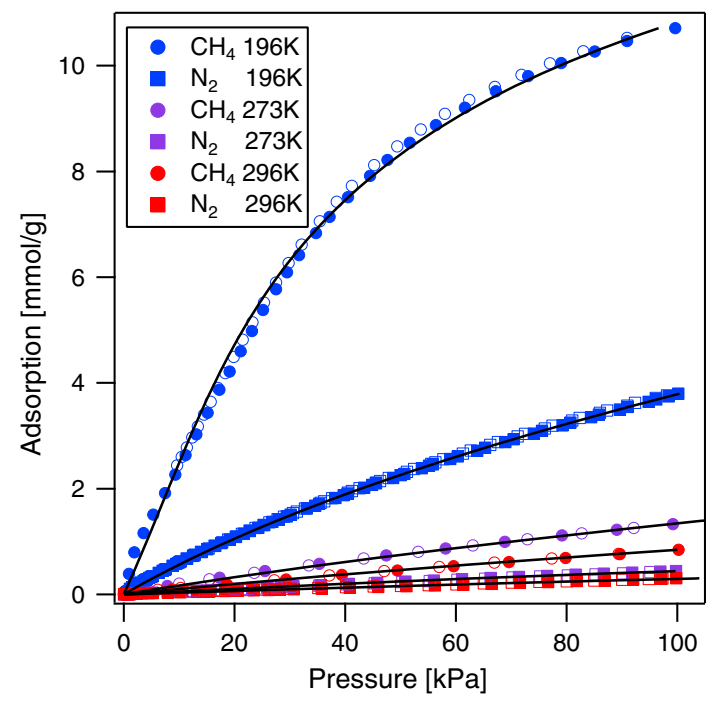

Fig. 3 Adsorption isotherms of $\mathrm{CH}_{4}$ and $\mathrm{N}_{2}$ by HKUST-1 at 196, 273 and $296 \mathrm{~K}$. Filled symbols indicate adsorption and empty symbols indicate desorption measurement points

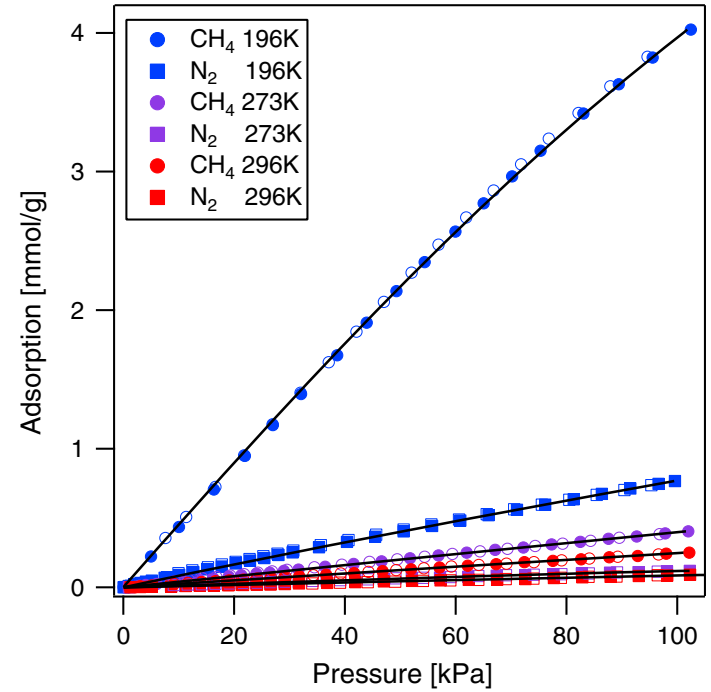

Fig. 4 Adsorption isotherms of $\mathrm{CH}_{4}$ and $\mathrm{N}_{2}$ by ZIF-8 at 196, 273 and 296 K. Filled symbols indicate adsorption and empty symbols indicate desorption measurement points

\subsection{Isosteric enthalpy of adsorption}

From the extracted fit coefficients, the isosteric enthalpy at zero adsorption amount $\left(\Delta \mathrm{H}_{0}\right)$ was determined using (3). Additionally, the isosteric enthalpy was calculated by a linear interpolation method at low adsorption amount and using (4). The results are presented in Table 1 and show that Z5A and HayeSep D have the highest enthalpy of methane adsorption while ZIF-8 exhibits the lowest (Fig. 7). For $N_{2}$ the molecular sieves showed the highest 


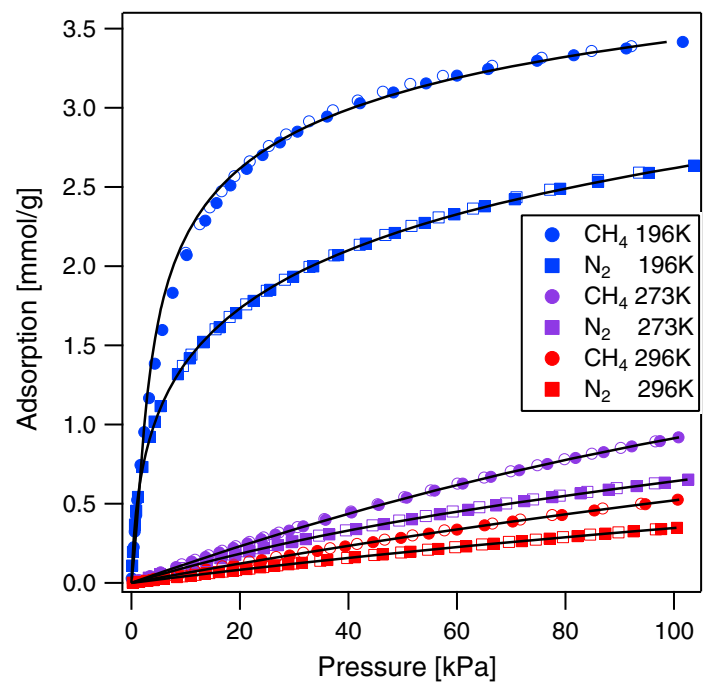

Fig. 5 Adsorption isotherms of $\mathrm{CH}_{4}$ and $\mathrm{N}_{2}$ by zeolite $5 \mathrm{~A}$ at 196, 273 and 296 K. Filled symbols indicate adsorption and empty symbols indicate desorption measurement points

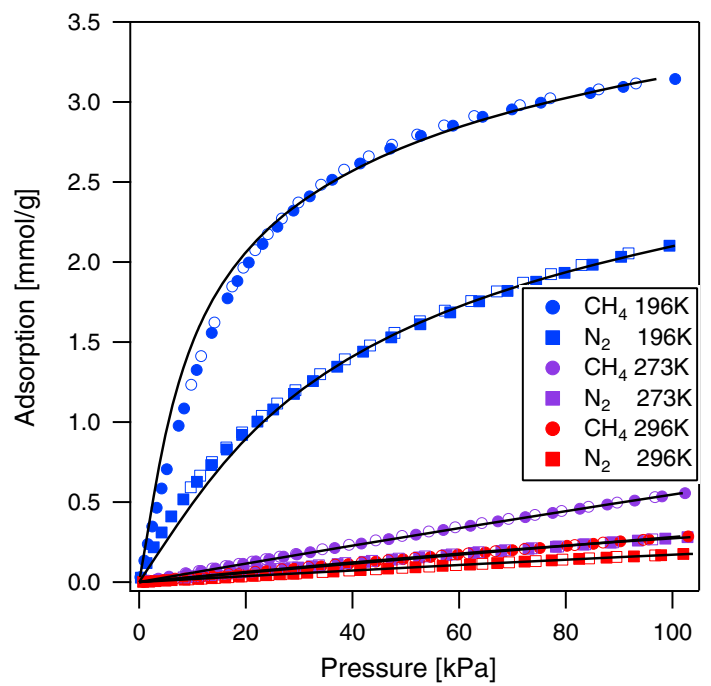

Fig. 6 Adsorption isotherms of $\mathrm{CH}_{4}$ and $\mathrm{N}_{2}$ by zeolite $13 \mathrm{X}$ at 196 , 273 and 296 K. Filled symbols indicate adsorption and empty symbols indicate desorption measurement points

enthalpy of adsorption and ZIF-8 the lowest. This will be discussed in more detail in Sect. 4.4. In Table 1, the $\Delta H_{0}$ values calculated by the linear interpolation method are compared with those from the virial method.

\subsection{Surface area}

Figures 8 and 9 show the $\mathrm{N}_{2}$ and $\mathrm{CH}_{4}$ adsorption isotherms of the candidate materials at $77 \mathrm{~K}$. The data were fitted with both the Langmuir and the BET model, and the surface area was calculated according to convention (Gregg

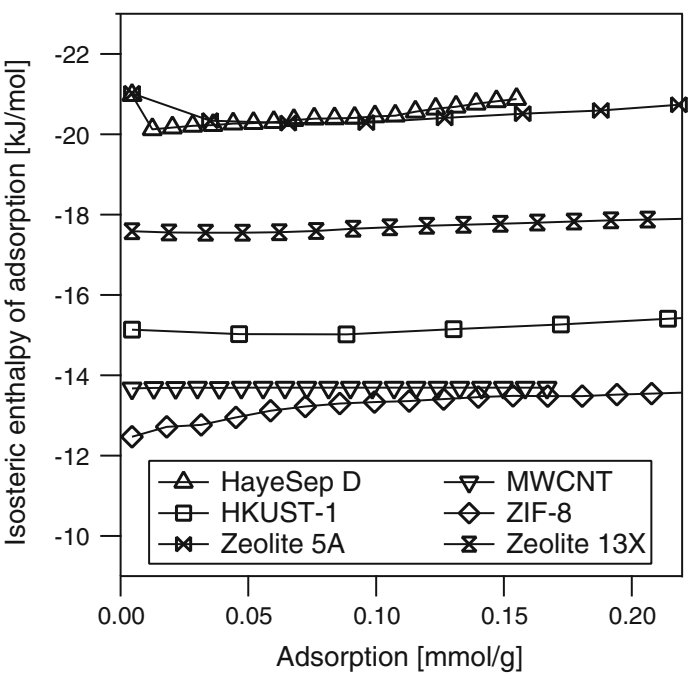

Fig. 7 Isosteric enthalpy as a function of $\mathrm{CH}_{4}$ adsorption amount in $\mathrm{mmol} / \mathrm{g}$ estimated by a linear interpolation method and applying the Clausius-Clapeyron equation (4)

and Sing 1991). The shape of the $\mathrm{CH}_{4}$ isotherms are very similar to those of $\mathrm{N}_{2}$, except that the saturation pressure is lower for $\mathrm{CH}_{4}$. For $\mathrm{N}_{2}$ the occupied surface area per molecule was taken to be $0.162 \mathrm{~nm}^{2}$ (Gregg and Sing 1991) and $0.1918 \mathrm{~nm}^{2}$ for $\mathrm{CH}_{4}$ (Chaix et al. 1996). The Langmuir model has a better agreement with the $\mathrm{N}_{2}$ adsorption isotherms for the MOFs and the zeolites, presumably because of their monolayer-like adsorption behavior due to very narrow pores. For HayeSep D and MWCNT the $\mathrm{N}_{2}$ and $\mathrm{CH}_{4}$ adsorption curves show a multilayer behavior with a linear uptake according to Henry's law above $\approx 2 \mathrm{kPa}$; thus the BET-model is more suitable. This behavior can be rationalized by the macroporous structure of these materials. Table 1 shows the surface areas of materials calculated using the BET and the Langmuir method for both adsorbates. To indicate limited agreement between the experimental data and the model fit, some values are given in parentheses (see Online Resource for more information). The MOFs exhibit by far the highest surface of 1450 $1700 \mathrm{~m}^{2} / \mathrm{g}$. MWCNT, on the other hand, show a relatively low surface area of $350-500 \mathrm{~m}^{2} / \mathrm{g}$.

\subsection{Selectivity}

Mixing ratios of $\mathrm{CH}_{4}$ in background air are less than 2 ppm, compared to around $78 \%$ for $\mathrm{N}_{2}$. In order to efficiently preconcentrate $\mathrm{CH}_{4}$ to levels suitable for analysis, it is important that the adsorptive properties of the chosen adsorbent are largely superior for $\mathrm{CH}_{4}$ over $\mathrm{N}_{2}$. Thus, the adsorptive selectivity of $\mathrm{CH}_{4}$ is perhaps the most important criterion for selection of an adsorbent for this purpose. This selectivity can be determined in several ways. A simplified and conventional approach is to compare $\mathrm{CH}_{4}$ and $\mathrm{N}_{2}$ 


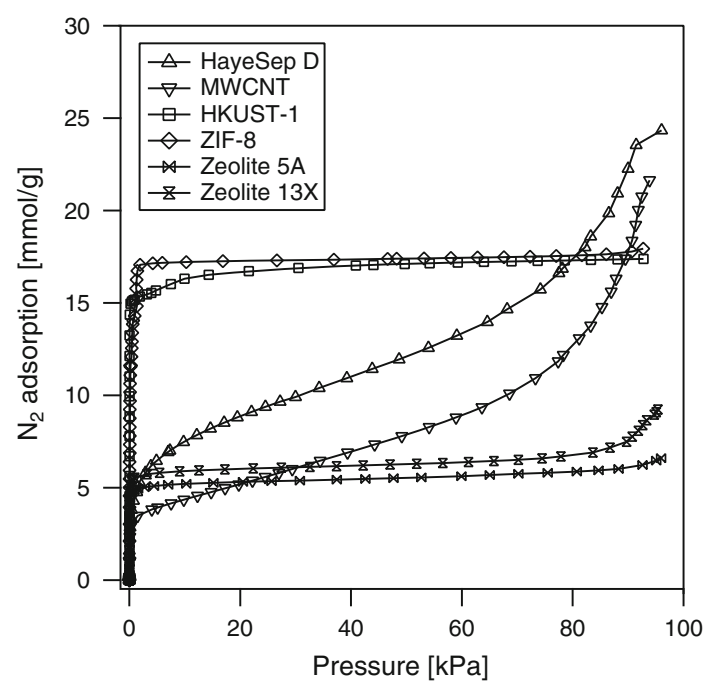

Fig. 8 Adsorption isotherms of $\mathrm{N}_{2}$ at $77 \mathrm{~K}$ for all candidate materials. Experimental data is fitted with the Langmuir and the BET model in order to extract the surface area

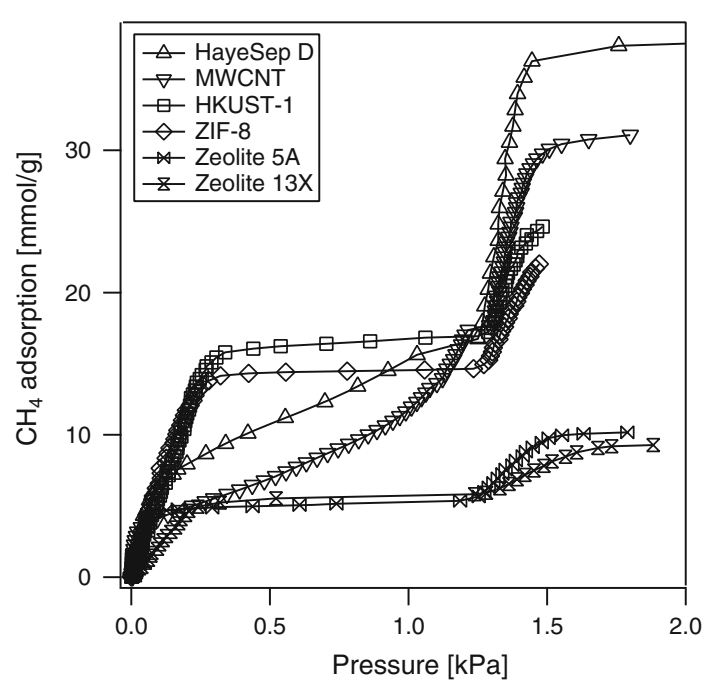

Fig. 9 Adsorption isotherms of $\mathrm{CH}_{4}$ at $77 \mathrm{~K}$ for all candidate materials. Experimental data is fitted with the Langmuir and the BET model in order to extract the surface area

adsorption capacity, determined in separate experiments but under identical conditions (Wiersum et al. 2013). For example selectivities of various MOFs and other materials for different gas compounds have been investigated by comparing the equilibrium adsorption capacity at specific conditions (Li et al. 2009; Pawar et al. 2009). In cationexchanged zeolite mordenite and MOFs, selective properties have been quantified by taking the ratio of the Henry's constants or comparing the isosteric enthalpy of adsorption of each gas (Peter et al. 2005; Liu et al. 2008; Moellmer et al. 2012). More sophisticated methods of measuring the selectivity of $\mathrm{CH}_{4}$ adsorption over $\mathrm{N}_{2}$ adsorption are also reported, for example breakthrough measurements, however these experiments are tailored to specific process conditions and require elaborate experimental apparatus beyond the scope of this study.

In this study, we focus on estimating the selectivity in two ways defined by the parameters $X$ and $Y$, which are given by Eq. (5) and (6). As mentioned before, both values are mainly discussed for a comparative assessment of candidate adsorbents. Variable $X$ gives the ratio of the binding energy of a distinct adsorbent for $\mathrm{CH}_{4}$ in relation to $\mathrm{N}_{2}$ gas. Variable $Y$ stands for the ratio of capacity at $196 \mathrm{~K}$ and $100 \mathrm{kPa}$ for $\mathrm{CH}_{4}$ relative to $\mathrm{N}_{2}$. This value is particularly interesting, as it represents the selectivity near the saturation point, where Henrys law is less dominant. The respective ratios $X$ and $Y$ are given in Table 1, which reveals that both approaches are in good agreement. HayeSep D and ZIF-8 show the most promising properties in terms of selectivity. Due to its weaker $\Delta H_{a d s}$, one must consider, however, that ZIF-8 is not saturated at $100 \mathrm{kPa}$ for either gas component and thus the ratio of adsorption of $\mathrm{CH}_{4}$ and $\mathrm{N}_{2}$ in this pressure range is not fully comparable to the other materials. This means that the value of $Y$ is more significant for ZIF-8 in terms of selectivity and, thus, HayeSep D shows the best selectivity of all materials, followed by ZIF-8, HKUST-1 and MWCNT. A similar conclusion can be drawn from Fig. 11, where the adsorption ratio have been calculated continuously in the range of 0-100 $\mathrm{kPa}$ and $200-300 \mathrm{~K}$ using the virial equation fits. While one must exercise caution when interpolating the data taken from only three isotherms, Fig. 11 is meant to show a qualitative comparison of the effects of temperature and pressure on the selectivity of each material. There are two main conclusions drawn from this plot. First, HayeSep $\mathrm{D}$ offers the most promising selective properties under most conditions while the molecular sieves show the least, which is consistent with the information derived from the isosteric enthalpy of adsorption for $\mathrm{CH}_{4}$ and $\mathrm{N}_{2}$. Secondly, the selective behavior of the adsorbents studied is more or less constant in the analyzed temperature and pressure regime, with one exception: namely, HayeSep D at low pressures and temperatures. In this region, HayeSep D exhibits an enhanced selectivity compared to the other candidate materials which can be directly evidenced in the measured isotherms at $196 \mathrm{~K}$. Zeolites 5A and 13X exhibit a low selectivity, with $\Delta H_{\text {ads }}$ being higher for $\mathrm{N}_{2}$ than for $\mathrm{CH}_{4}$, which excludes them from being suitable candidates for this application.

\subsection{Temperature behavior}

To optimize the effectiveness of a preconcentration unit, it is important to find the ideal regime where selectivity and 
Table 1 Physical properties of the tested adsorbents for $\mathrm{CH}_{4}$

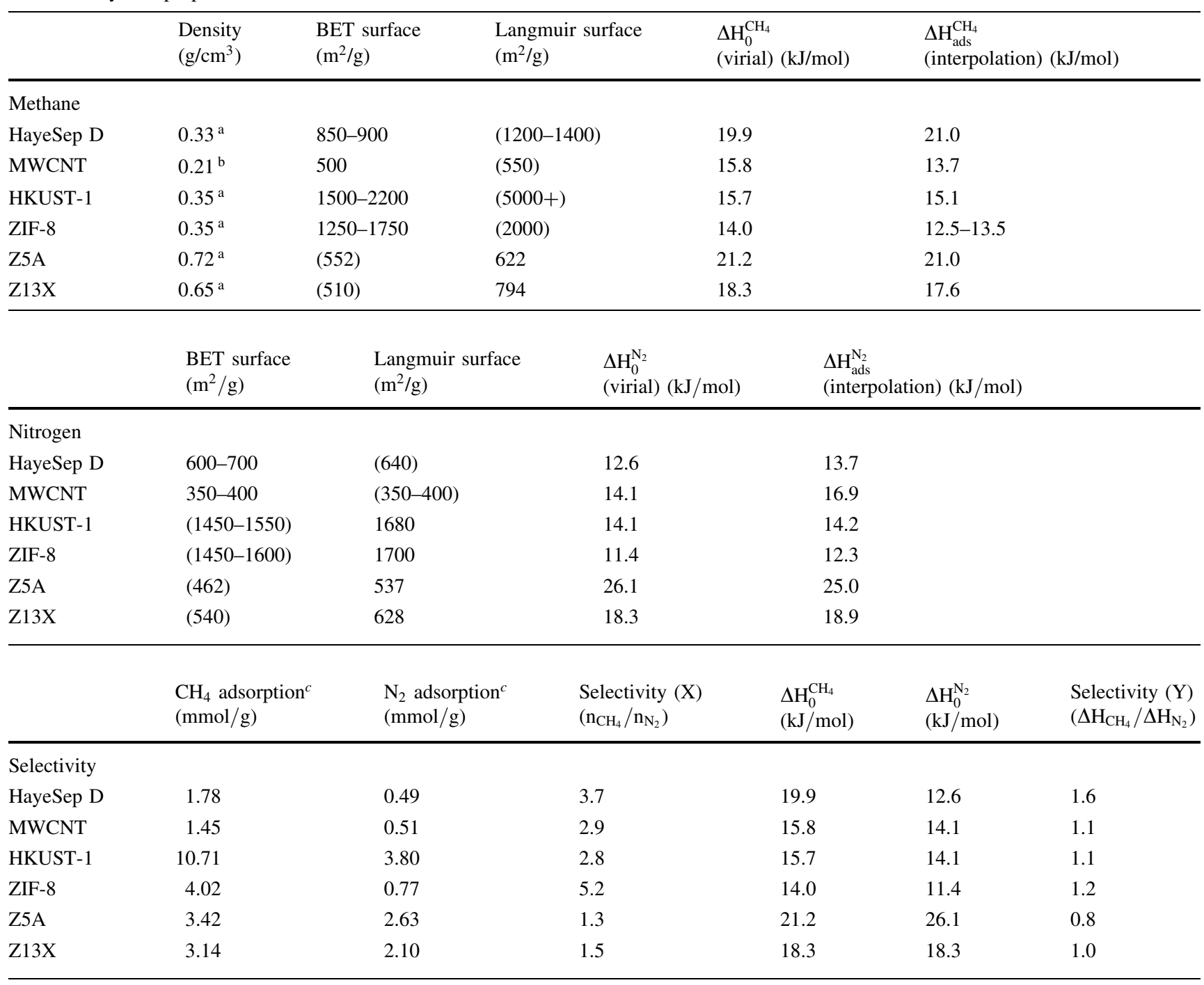

Values in parentheses indicate limited agreement between the experimental data and the model

a Sigma Aldrich

b Cheap tubes Inc. Values in parentheses indicate limited agreement between the experimental data and the model

c Excess adsorption amount at $100 \mathrm{kPa}$ at $196 \mathrm{~K}$ for $\mathrm{CH}_{4}$ and $\mathrm{N}_{2}$ respectively

adsorption capacity are optimized for both adsorption, and desorption conditions. Such optimization processes have been useful in other reported applications (Wurzbacher et al. 2011; Harpalani 2006). For example, thermogravimetric measurements on functionalized silica-gel were fitted to isotherm models and the results successfully applied to predict desorption capacities and optimize a temperature-vacuum swing process to capture $\mathrm{CO}_{2}$ (Wurzbacher et al. 2011). Using the fitted isotherm data, it is possible to construct new isotherms within the regime measured to identify the best temperature ranges for obtaining maximum adsorption capacity and rapid desorption. Figure 10 shows the $\mathrm{CH}_{4}$ adsorption isotherms of all adsorbent materials as a function of pressure and temperature; temperatures below $200 \mathrm{~K}$ are found to be most promising because the adsorption capacity increases considerably with decreasing temperature, while the $\mathrm{CH}_{4} / \mathrm{N}_{2}$ selectivity increases or stays more or less constant (Fig. 11). This is particularly noticeable in the low pressure regime, while at atmospheric pressures $\mathrm{CH}_{4}$ adsorption may saturate.

The practicality of lowering the adsorption temperature, however, is limited by cooling power of the system and the possibility of affecting other components. The two MOF candidates show a similar $\mathrm{CH}_{4}$ adsorption behavior at $77 \mathrm{~K}$ (Fig. 9), but HKUST-1 has a much higher adsorption 


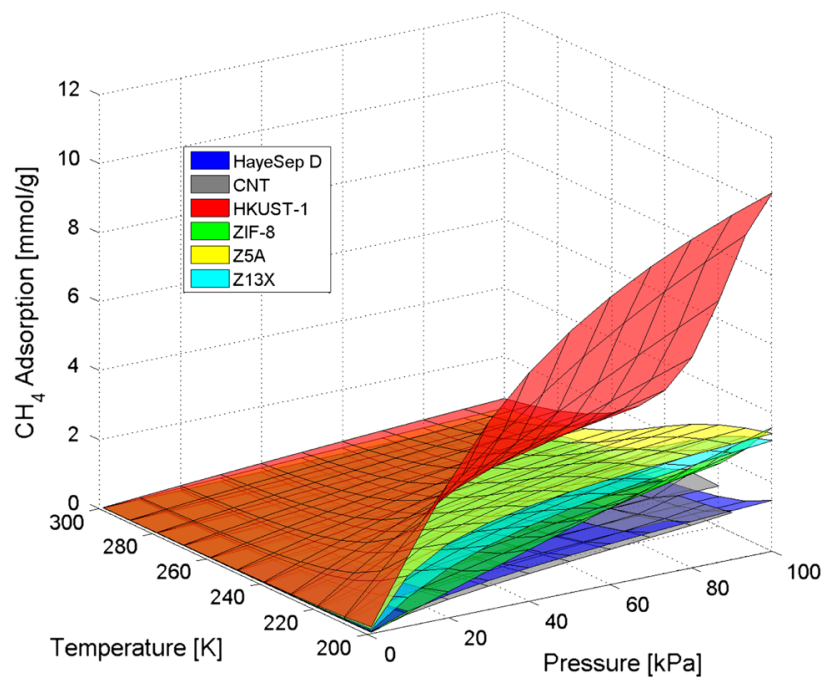

Fig. 10 Methane adsorption capacity for all materials as a function of pressure and temperature. Data is interpolated by the virial-model

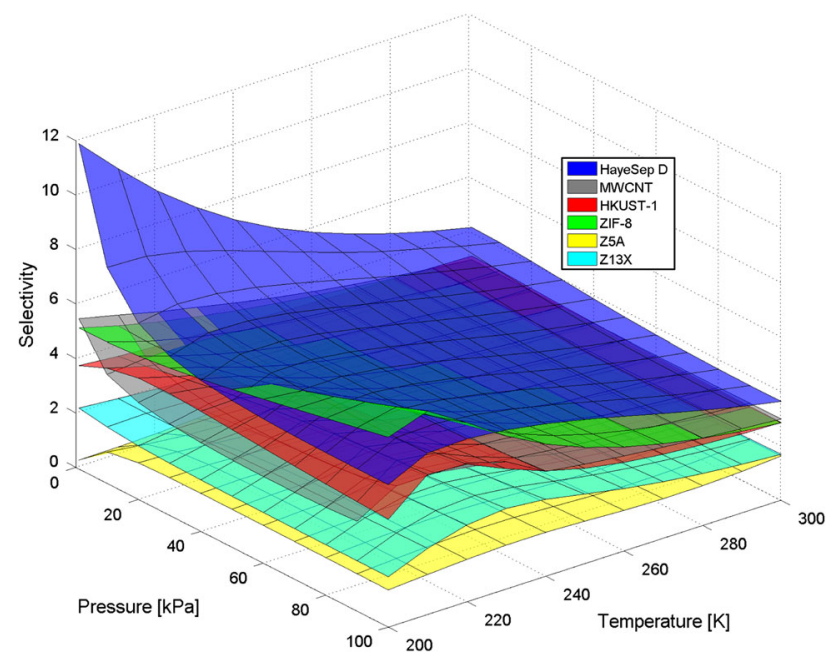

Fig. 11 Three-dimensional plot of the $\mathrm{CH}_{4} / \mathrm{N}_{2}$-Selectivity as a function of pressure and temperature for all materials generated from virial modeling of isotherms

capacity at $196 \mathrm{~K}$ (Fig. 10). This is attributed to the low isosteric enthalpy of adsorption of ZIF-8 for $\mathrm{CH}_{4}$ (Table 1). Therefore, ZIF- 8 may be a promising adsorbent for methane preconcentration when the necessary cooling conditions are available.

Practically, the desorption temperature can be as high as necessary. A temperature of $\approx 273 \mathrm{~K}$ should be sufficient to desorb $99.99 \%$ of the captured $\mathrm{CH}_{4}$, as it has showed to be an ideal regime for the desorption of $\mathrm{N}_{2} \mathrm{O}$ from HayeSep D (Mohn et al. 2010). The optimal desorption temperature is likely to follow with the isosteric enthalpy of adsorption for $\mathrm{CH}_{4}$, so that for example ZIF-8 would retain even less $\mathrm{CH}_{4}$ than HayeSep D at $\approx 273 \mathrm{~K}$.

\subsection{Co-adsorption}

Methane adsorption from ambient air represents a big challenge as a very small volumetric mixing ratio around 2 $\times 10^{-6}$ has to be separated from many other gases, such as $\mathrm{N}_{2}$ (78\%), oxygen $(20.9 \%)$, argon $(0.9 \%)$, water vapor (variable content), carbon dioxide $\left(400 \times 10^{-6}\right)$ and nitrous oxide $\left(0.3 \times 10^{-6}\right)$. The focus of the presented study was on the separation of $\mathrm{CH}_{4}$ from $\mathrm{N}_{2}$, which is by far the dominating component in ambient air. With respect to our target application it is not necessary to address possible coadsorption differences between the materials with respect to oxygen $\left(\mathrm{O}_{2}\right)$, argon (Ar) and other noble gases, assuming that in a first approximation, the effects will be similar for the materials studied. Nonetheless, additional experiments on the separation of $\mathrm{O}_{2}$ and $\mathrm{Ar}$ may be needed for other applications. Similarly, the adsorption of carbon dioxide $\left(\mathrm{CO}_{2}\right)$ and water vapor $\left(\mathrm{H}_{2} \mathrm{O}\right)$ is of minor importance because both are routinely removed prior to $\mathrm{CH}_{4}$ adsorption in the envisaged analytical applications (Mohn et al. 2010; Bock et al. 2010). Nitrous oxide $\left(\mathrm{N}_{2} \mathrm{O}\right)$ has much lower ambient air mixing ratios and a higher boiling point than $\mathrm{CH}_{4}$. Therefore, it is of lower importance and could be separated by selective desorption.

\subsection{Limits of the approach}

Additionally to the limits mentioned in Sects. 4.4 and 4.6 there are also other considerations to make for this approach. The proposed material selection methodology focuses entirely on adsorptive selectivity, but does not consider any other properties which may be relevant, such as dispersion coefficients or thermal conductivity (Wiersum et al. 2013; Saridara et al. 2010). The former is due to the kinetic behavior of gases inside the pores and is thus related to the pore-size distribution of the adsorbent. The kinetic behavior of gases inside the pores of zeolites is well known, and also investigated for MOFs (Yaremov et al. 2013; Li et al. 2009). Thermal conductivity is important in order to remove the large amount of heat being added to the system by the adsorbed gas. While these general material properties may be known, the behavior of a specific setup is difficult to predict. Therefore, these properties are best determined in breakthrough experiments which reflect the conditions that are expected for the target preconcentration setup. Our approach is based on the approximation of the selectivity of $\mathrm{CH}_{4}$ over $\mathrm{N}_{2}$. While this is a valuable first approximation, it may not reflect the full 
complexity of the kinetic effects that are present during methane preconcentration of ambient air.

\section{Conclusion}

In this study we have systematically evaluated six adsorbent materials for the application of high volume preconcentration of ambient air, with the aim of categorizing each material in adsorption capacity and $\mathrm{CH}_{4} / \mathrm{N}_{2}$-selectivity. For effective high volume preconcentration, the overall adsorption capacity becomes a critical parameter in addition to $\mathrm{CH}_{4} / \mathrm{N}_{2}$-selectivity. Thus, HKUST-1 is highly promising due to its good selectivity and exceptional total adsorption capacity compared to HayeSep D. ZIF-8 also exhibits a high surface area, which is similar to HKUST-1, and even better selective properties. However, due to the weak binding interaction of ZIF-8 with $\mathrm{CH}_{4}$, its adsorption capacity is lower compared to HayeSep D in the low pressure and high temperature regime. MWCNT exhibits a good selectivity, but the overall adsorption capacity is much lower then HayeSep D or HKUST-1. Carbon nanotubes with higher surface areas could therefore also be promising materials, especially because of their high thermal conductivity (Saridara et al. 2010; Han and Fina 2011). The zeolites have a low adsorption capacity and the lowest selectivity making them the least suitable candidates according to this study.

In conclusion, our data confirms that HayeSep D, a frequently used adsorbent for analytical preconcentration applications, is a suitable choice. It has a respectable adsorption capacity and the highest overall selectivity. The optimal adsorbent, however, would have a higher surface area combined with the isosteric enthalpy and selectivity of HayeSep D. We therefore suggest that a microporous equivalent of HayeSep D would be an ideal future material for this purpose. The approach used in this study is suitable for identifying candidate materials for high volume preconcentration of $\mathrm{CH}_{4}$ from ambient air, and can easily be extended by additional gas compounds such as $\mathrm{O}_{2}, \mathrm{Ar}$ and $\mathrm{N}_{2} \mathrm{O}$, as well as to other applications.

Acknowledgments Funding from the Swiss National Foundation for Scientific Research (SNF) and the EU funded INGOS is gratefully acknowledged. We thank Prof. Ulrich Müller from BASF and Prof. Hubertus Fischer from University of Bern for helpful discussions.

Open Access This article is distributed under the terms of the Creative Commons Attribution License which permits any use, distribution, and reproduction in any medium, provided the original author(s) and the source are credited.

\section{References}

Bimbo, N., Ting, V.P., Hruzewicz-Koodziejczyk, A., Mays, T.J.: Analysis of hydrogen storage in nanoporous materials for low carbon energy applications. Faraday Discuss. 151, 59-74 (2011)

Bock, M., Schmitt, J., Behrens, M., Mueller, L., Schneider, R., Sapart, C., Fischer, H.: A gas chromatography/pyrolysis/isotope ratio mass spectrometry system for high-precision $\delta \mathrm{D}$ measurements of atmospheric methane extracted from ice cores. Rapid Commun. Mass Spectrom. 24(5), 621-633 (2010)

Chaix, L., Ocampo, J., Domin, F.: Adsorption of $\mathrm{CH}_{4}$ on laboratorymade crushed ice and on natural snow at $77 \mathrm{k}$, atmospheric implications. C. R. de L'Acad. de Sci - Ser. IIa: Sci de la Terre et des Planetes, 322(8):609-616 (1996)

Czepirski, L., Jagiello, J.: Virial-type thermal equation of gas-solid adsorption. Chem. Eng. Sci. 44, 797-801 (1989)

Delgado, J., Agueda, V., Uguina, M., Sotelo, J., Fernandez, P.: Adsorption and diffusion of nitrogen, methane and carbon dioxide in aluminophosphate molecular sieve AlPO4-11. Adsorption 19, 407-422 (2013)

Dettmer, K., Engewald, W.: Adsorbent materials commonly used in air analysis for adsorptive enrichment and thermal desorption of volatile organic compounds. Anal. Bioanal. Chem. 373(6), 490-500 (2002)

Dren, T., Sarkisov, L., Yaghi, O.M., Snurr, R.Q.: Design of new materials for methane storage. Langmuir 20(7), 2683-2689 (2004)

Falkovich, A., Rudich, Y.: Analysis of semivolatile organic compounds in atmospheric aerosols by direct sample introduction thermal desorption GCMS. Environ. Sci. Technol. 35(11), 2326-2333 (2001)

Fayet, P., Kaldor, A., Cox, D.M.: Palladium clusters: $\mathrm{H}_{2}, \mathrm{D}_{2}, \mathrm{~N}_{2}, \mathrm{CH}_{4}$, $\mathrm{CD}_{4}, \mathrm{C}_{2} \mathrm{H}_{4}$, and $\mathrm{C}_{2} \mathrm{H}_{6}$ reactivity and $\mathrm{D}_{2}$ saturation studies. J. Chem. Phys 92, 254-261 (1990)

Gregg, S., Sing, K.: Adsorption, Surface Area, and Porosity. Academic Press, London (1991)

Han, Z., Fina, A.: Thermal conductivity of carbon nanotubes and their polymer nanocomposites: a review. Prog. Polym. Sci. 36(7), 914-944 (2011)

Harpalani, S.: Methane/ $\mathrm{CO}_{2}$ sorption modeling for coalbed methane production and $\mathrm{CO}_{2}$ sequestration. Energy Fuels 20, 1591-1599 (2006). Equation

Koester, J.R. Well, R., Tuzson, B., Bol, R., Dittert, K., Giesemann, A., Emmenegger, L., Manninen, A., Crdenas, L., and Mohn, J.: Novel laser spectroscopic technique for continuous analysis of $\mathrm{N}_{2} \mathrm{O}$ isotopomers - application and intercomparison with isotope ratio mass spectrometry. Rapid Commun. Mass Spectrom. 27(1):216-222. Cited By (since 1996):1. (2013)

Li, H., Eddaoudi, M., O'Keeffe, M., Yaghi, O.: Design and synthesis of an exceptionally stable and highly porous metal-organic framework. Nature 402(6759), 276-279 (1999)

Li, J., Li, G., Jiang, F., Bu, J., Zhao, M., Zhan, H., Chu, Y.: Preparation of carbon molecular sieve for pressure swing adsorption concentrating low-concentration methane. Asian J. Chem. 24(12), 5493-5496 (2012)

Li, J.-R., Kuppler, R.J., Zhou, H.-C.: Selective gas adsorption and separation in metal-organic frameworks. Chem. Soc. Rev. 38, 1477-1504 (2009)

Liu, B., Yang, Q., Xue, C., Zhong, C., Chen, B., Smit, B.: Enhanced adsorption selectivity of hydrogen/methane mixtures in metal organic frameworks with interpenetration: A molecular simulation study. J. Phys. Chem. C 112(26), 9854-9860 (2008) 
Lu, J.-Y., Liu, W., Sun, L.-B., Liu, X.-Q.: Adsorption equilibrium and separation of methane and carbon dioxide mixtures on $13 \mathrm{X}$ molecular sieve. J. Chem. Eng. Data 27(1), 1-6 (2013)

Mendoza-Cortes, J.L.: Adsorption mechanism and uptake of methane in covalent organic frameworks: theory and experiment. J. Phys. Chem. A 114, 10824-10833 (2010)

Moellmer, J., Lange, M., Moeller, A., Patzschke, C., Stein, K., Laessig, D., Lincke, J., Glaeser, R., Krautscheid, H., and Staudt, R.: Pure and mixed gas adsorption of $\mathrm{CH}_{4}$ and $\mathrm{N}_{2}$ on the metalorganic framework basolite A100 and a novel copper-based 1,2,4-triazolyl isophthalate mof. J. Mater. Chem. 22(20):10274-10286. cited By (since 1996)6. (2012)

Moellmer, J., Moeller, A., Dreisbach, F., Glaeser, R., Staudt, R.: High pressure adsorption of hydrogen, nitrogen, carbon dioxide and methane on the metal-organic framework HKUST-1. Microporous Mesoporous Mater. 138(1-3), 140-148 (2011)

Mohn, J., Guggenheim, C., Tuzson, B., Vollmer, M., Toyoda, S., Yoshida, N., Emmenegger, L.: A liquid nitrogen-free preconcentration unit for measurements of ambient $\mathrm{N}_{2} \mathrm{O}$ isotopomers by QCLAS. Atmos. Meas. Tech. 3(3), 609-618 (2010)

Mohn, J., Tuzson, B., Manninen, A., Yoshida, N., Toyoda, S., Brand, W.A., Emmenegger, L.: Site selective real-time measurements of atmospheric $\mathrm{N}_{2} \mathrm{O}$ isotopomers by laser spectroscopy. Atmos. Meas. Tech. 5(7), 1601-1609 (2012)

Pawar, R.R., Patel, H.A., Sethia, G., Bajaj, H.C.: Selective adsorption of carbon dioxide over nitrogen on calcined synthetic hectorites with tailor-made porosity. Appl. Clay Sci. 46(1), 109-113 (2009)

Peter, S.A., Sebastian, J., Jasra, R.V.: Adsorption of nitrogen, oxygen, and argon in mono-, di-, and trivalent cation-exchanged zeolite mordenite. Ind. Eng. Chem. Res. 44(17), 6856-6864 (2005)

Phillips, J.T., Van Hook, W.A.: Gas chromatography of perdeuteriomethane. Isotope effect on adsorption on porous glass. J. Phys. Chem. 71, 3276-3279 (1967)

Reimann, S., Vollmer, M., Folini, D., Steinbacher, M., Hill, M., Buchmann, B., Zander, R., Mahieu, E.: Observations of longlived anthropogenic halocarbons at the high-alpine site of Jungfraujoch (Switzerland) for assessment of trends and european sources. Sci. Total Environ. 391(2-3), 224-231 (2008)

Saridara, C., Ragunath, S., Pu, Y., Mitra, S.: Methane preconcentration in a microtrap using multiwalled carbon nanotubes as sorbents. Anal. Chim. Acta 677(1), 50-54 (2010)

Sing, K.: The use of nitrogen adsorption for the characterisation of porous materials. Colloids Surf. A 187-188, 3-9 (2001)

Solomon, S.: Contribution of Working Group I to the Fourth Assessment Report of the Intergovernmental Panel on Climate Change. Technical Report. Cambridge University Press, (2007)

Stadie, N.: Synthesis and Thermodynamic Studies of Physisorptive Energy Storage Materials. PhD thesis, CalTech. (2012)

Stadie, N., Murialdo, M., Ahn, C., Fultz, B.: Anomalous isosteric enthalpy of adsorption of methane on zeolite-templated carbon. J. Am. Chem. Soc. 135(3), 990-993 (2013)

Thammakhet, C., Thavarungkul, P., Brukh, R., Mitra, S., Kanatharana, P.: Microtrap modulated flame ionization detector for on- line monitoring of methane. J. Chromatogr. A 1072(2), 243-248 (2005)

Tuzson, B., Henne, S., Brunner, D., Steinbacher, M., Mohn, J., Buchmann, B., Emmenegger, L.: Continuous isotopic composition measurements of tropospheric $\mathrm{CO}_{2}$ at Jungfraujoch $(3580 \mathrm{~m}$ a.s.1.), Switzerland: real-time observation of regional pollution events. Atmos. Chem. Phys. 11(4), 1685-1696 (2011)

Tuzson, B., Mohn, J., Zeeman, M., Werner, R., Eugster, W., Zahniser, M., Nelson, D., McManus, J., Emmenegger, L.: High precision and continuous field measurements of $\delta^{13} \mathrm{C}$ and $\delta^{18} \mathrm{O}$ in carbon dioxide with a cryogen-free qclas. Appl. Phys. B 92, 451-458 (2008)

Wang, Z.-M., Arai, T., Kumagai, M.: Adsorption separation of low concentrations of $\mathrm{CO}_{2}$ and $\mathrm{NO}_{2}$ by synthetic zeolites. Energy Fuels 12(6), 1055-1060 (1998)

Werner, R., Brand, W.: Referencing strategies and techniques in stable isotope ratio analysis. Rapid Commun. Mass Spectrom. 15(7), 501-519 (2001)

Wiersum, A., Chang, J.-S., Serre, C., Llewellyn, P.: An adsorbent performance indicator as a first step evaluation of novel sorbents for gas separations: application to metal-organic frameworks. Langmuir 29(10), 3301-3309 (2013)

Wong, G., Ng, S., Webster, R.: Quantitative analysis of atmospheric volatile organic pollutants by thermal desorption gas chromatography mass spectrometry. Anal. Methods 5(1), 219-230 (2013)

Wu, C.-H., Lin, M.-N., Feng, C.-T., Yang, K.-L., Lo, Y.-S., Lo, J.-G.: Measurement of toxic volatile organic compounds in indoor air of semiconductor foundries using multisorbent adsorption/thermal desorption coupled with gas chromatography-mass spectrometry. J. Chromatogr. A 996(1-2), 225-231 (2003)

Wu, H.: Metaorganic frameworks with exceptionally high methane uptake: where and how is methane stored? Chem. A Eur. J. 16, 5205-5214 (2010)

Wunderlin, P., Lehmann, M., Siegrist, H., Tuzson, B., Joss, A., Emmenegger, L., Mohn, J.: Isotope signatures of $\mathrm{N}_{2} \mathrm{O}$ in a mixed microbial population system: constraints on $\mathrm{N}_{2} \mathrm{O}$ producing pathways in wastewater treatment. Environ. Sci. Technol. 47(3), 1339-1348 (2013)

Wunderlin, P., Mohn, J., Joss, A., Emmenegger, L., Siegrist, H.: Mechanisms of $\mathrm{N}_{2} \mathrm{O}$ production in biological wastewater treatment under nitrifying and denitrifying conditions. Water Res. 46(4), 1027-1037 (2012)

Wurzbacher, J.A., Gebald, C., Steinfeld, A.: Separation of $\mathrm{CO}_{2}$ from air by temperature-vacuum swing adsorption using diaminefunctionalized silica gel. Energy Environ. Sci. 4, 3584-3592 (2011)

Yaremov, P., Scherban, N., Ilyin, V.: Adsorption of nitrogen, hydrogen, methane, and carbon oxides on micro- and mesoporous molecular sieves of different nature. Theor. Exp. Chem. 48, 394-400 (2013) 